\title{
Thermogravimetric Analysis of Coal Semi-Char Co-Firing with Straw in $\mathrm{O}_{2} / \mathrm{CO}_{2}$ Mixtures
}

\author{
Debo Li ${ }^{1,2, *}$, Ning Zhao ${ }^{2}$, Yongxin Feng ${ }^{2}$ and Zhiwen Xie ${ }^{2}$ \\ 1 Guangdong Electric Power Research Institute, Guangzhou 510663, China \\ 2 China Southern Power Grid Technology Co., Ltd., Guangzhou 510080, China; 15088050825@163.com (N.Z.); \\ yongxingf@126.com (Y.F.); xiezhiwen@126.com (Z.X.) \\ * Correspondence: 1dbyx@126.com
}

Citation: Li, D.; Zhao, N.; Feng, Y.; Xie, Z. Thermogravimetric Analysis of Coal Semi-Char Co-Firing with Straw in $\mathrm{O}_{2} / \mathrm{CO}_{2}$ Mixtures. Processes 2021, 9, 1421. https://doi.org/ $10.3390 /$ pr9081421

Academic Editor: Song Hu

Received: 14 July 2021

Accepted: 11 August 2021

Published: 17 August 2021

Publisher's Note: MDPI stays neutral with regard to jurisdictional claims in published maps and institutional affiliations.

Copyright: (c) 2021 by the authors. Licensee MDPI, Basel, Switzerland. This article is an open access article distributed under the terms and conditions of the Creative Commons Attribution (CC BY) license (https:// creativecommons.org/licenses/by/ $4.0 /)$.

\begin{abstract}
For coal semi-char as a by-produced of low-temperature pyrolysis, combustion for power generation is one of the effective utilization methods to realize its clean and efficient utilization. However, the coal semi-char combustion process has a difficult ignition, unstable combustion and low burnout rate. The co-firing of the semi-char with biomass under oxy-fuel conditions can improve the combustion behavior and reduce fossil $\mathrm{CO}_{2}$ emissions. In this paper, the combustion behavior of Shenhua coal semi-char (SHC) co-firing with straw (ST) in $\mathrm{O}_{2} / \mathrm{CO}_{2}$ mixture is investigated using thermogravimetric analysis. The results show that each curve lays between those of the individual fuels and presents three peaks (i.e., three stages). The thermogravimetric curves of SHC co-firing with ST can be divided into three stages: the volatile combustion of ST, the co-combustion of SHC and ST fixed-carbons and the SHC fixed-carbon combustion and the decomposition of the difficult pyrolytic material of ST. Blending ST into the SHC can significantly decrease the ignition temperature and improve the comprehensive combustion behavior of blended samples. In increasing the proportion of ST from 25 to $100 \%$, the change of the blended ignition temperature is slight, but the burnout temperature decreases greatly. Kinetic parameters of combustion are calculated by using the CoatsRedfern integral method. Compared to that of stage I and stage III, the activation energy of stage II is significantly lower. As increasing blending ratio from $25 \%$ to $100 \%$, the activation energy increases at stage I and decreases at stage III. Furthermore, the $\mathrm{O}_{2}$ concentration obviously affects stage III of 50\% SHC $+50 \%$ ST, and the thermogravimetric curves at this stage are obviously shifted to the lower temperature zone as the $\mathrm{O}_{2}$ concentration increases. The activation energy of $50 \%$ $\mathrm{SHC}+50 \%$ ST increases as the oxygen concentration increases. Besides, the activation energy shows that the combustion characteristics cannot be determined only by the activation energy obtained by the Coats-Redfern method. These findings can provide useful information for semi-char co-firing with biomass.
\end{abstract}

Keywords: semi-char; biomass; co-firing; oxy-fuel; thermogravimetric analysis; kinetic analysis

\section{Introduction}

In China, the low-rank coal (such as lignite and subbituminous coal) accounts for above $50 \%$ of the total (141,595 million tons at the end of 2019 from BP Statistical Review of World Energy 2020) [1,2]. Pyrolysis is one of the most effective methods to realize the high and clean, efficient utilization of low-rank coal [3-5]. The pyrolysis process at low temperature and low heating rate produce the by-product semi-char with lower moisture and volatile contents [6]. With the rapid development of the coal chemical industry, there is a large amount of semi-char in China. For the coal semi-char, combustion for power generation is one of the effective utilization methods to realize its clean and efficient utilization [7]. However, the coal semi-char combustion has many problems in actual utilization, such as poor ignition, low burnout rate, etc. [8].

In order to solve these difficulties of the coal semi-char combustion, many efforts have been performed. The preheating combustion technology is one of the effective methods and 
has been widely studied recently $[5,9,10]$. However, the preheating combustion technology may be uneconomic for existing utility boilers due to the high cost of preheating equipment. Co-combustion technology of coal semi-char with high-volatile fuels is also one of the effective methods. Zheng et al. [11] performed an experimental investigation on ignition and burnout characteristics of coal semi-char and bituminous coal blends, and the results show that the ignitability index and the comprehensive combustion characteristic index of the blends decrease as increasing the blending proportion of coal semi-char. Zhang et al. [12] investigated the co-combustion behaviors and NOx emissions of coal semi-char and bituminous coal, and results showed obvious promotion on burnout and superior inhibition on NOx formation when the coal semi-char accounted for $20 \%$. Moreover, there is a great supply of biomass but little use in China. As a renewable energy source, biomass has many advantages, such as better ignition and burnout behaviors and low pollution. Wang [13] and Liu et al. [14,15] studied the co-combustion behavior of coal semi-char with cornstalk, and good ignition and high burnout can be achieved when coal semi-char was co-fired with cornstalk. Especially in a real scale application, co-firing coal semi-char and straw may cause notable problems to the feeding system and the reactor. Pelletizing or co-pelletizing the materials may be a way to overcome this issue, although it could be unfeasible.

In addition, fossil fuel combustion is the dominant contributor to $\mathrm{CO}_{2}$ as a greenhouse gas and has received wide attention [16-19]. Oxy-fuel combustion is recognized as one of the promising $\mathrm{CO}_{2}$ reduction and capture technologies for fossil fuel combustion [20]. Meanwhile, biomass is also recognized as a zero- $\mathrm{CO}_{2}\left(\right.$ fossil $\left.\mathrm{CO}_{2}\right)$ renewable fuel. Therefore, co-firing with coal semi-char under oxy-fuel conditions may be one of the effective ways to improve the combustion characteristics and reduce fossil $\mathrm{CO}_{2}$ emissions. However, there are few studies on the coal semi-char co-firing with biomass under oxy-fuel conditions. It is necessary to investigate the co-firing behavior of coal semi-char and biomass in the oxy-fuel atmosphere. In this study, the combustion behavior of coal semi-char co-firing with straw in $\mathrm{O}_{2} / \mathrm{CO}_{2}$ mixture is investigated using thermogravimetric analysis, which can provide useful information for coal semi-char co-firing with biomass in oxy-fuel conditions.

\section{Experiments}

\subsection{Samples Description}

This study chooses two fuels: Shenhua coal semi-char (SHC) and straw (ST). The straw was obtained from rice straw in Hubei. The proximate and ultimate analysis of samples is listed in Table 1. The coal pyrolysis process at low temperature (below $800{ }^{\circ} \mathrm{C}$ ) and low heating rate produce the by-product semi-char with little volatile and rich pore structure. Additionally, in this study, a tubular furnace prepares the Shenhua coal semi-char (SHC). First, $1.0 \mathrm{~g}$ coal with a size of $75-150 \mu \mathrm{m}$ are spread evenly on the corundum magnetic boat bottom, and the corundum magnetic boat is pushed into the furnace. Then, the furnace is heated to $750{ }^{\circ} \mathrm{C}$ at a heating rate of $5{ }^{\circ} \mathrm{C} / \mathrm{min}$ under $\mathrm{N}_{2}$ atmosphere; then, the furnace is kept at $750^{\circ} \mathrm{C}$ about $30 \mathrm{~min}$. After the preparation, the corundum magnetic boat is pushed out and is flushed in $\mathrm{N}_{2}$ atmosphere to cool the sample.

Table 1. Proximate analysis and ultimate analysis of samples.

\begin{tabular}{ccccccccc}
\hline \multirow{2}{*}{ Samples } & \multicolumn{3}{c}{ Proximate Analysis (Dry, wt\%) } & \multicolumn{4}{c}{ Ultimate Analysis (Daf, wt\%) } \\
\cline { 2 - 9 } & Volatile Matter & Ash & Fixed Carbon & C & H & O & N & S \\
\hline Shenhua coal & 32.32 & 10.27 & 57.41 & 81.52 & 3.33 & 13.65 & 1.18 & 0.31 \\
SHC & 6.45 & 14.93 & 78.62 & 72.25 & 0.43 & 11.21 & 0.89 & 0.29 \\
ST & 75.90 & 10.75 & 13.35 & 48.22 & 6.62 & 33.05 & 1.06 & 0.31 \\
\hline
\end{tabular}

\subsection{Experimental Apparatus, Methods and Kinetic Method}

The combustion characteristics of samples are studied by using a thermogravimetric analyzer, as shown in Figure 1a. This small-scaled experiment can accurately and quantita- 
tively reflect some behaviors in the co-combustion processes of coal semi-char and straw in $\mathrm{O}_{2} / \mathrm{CO}_{2}$ mixtures, although a difference exists compared to the actual combustion in the large-scaled device. The $\mathrm{O}_{2}$ concentrations used in this study are 21, 30 and $40 \mathrm{vol} \%$, which are mixed with $\mathrm{CO}_{2}$ for a total flow rate of $100 \mathrm{~mL} / \mathrm{min}$ under the ambient temperature and pressure. A total of $10.00 \mathrm{mg}$ sample is heated from $50{ }^{\circ} \mathrm{C}$ to $800{ }^{\circ} \mathrm{C}$ with a heating rate of $20^{\circ} \mathrm{C} / \mathrm{min}$. Duplicate experiments for each test were performed in order to test the reproducibility of the results.

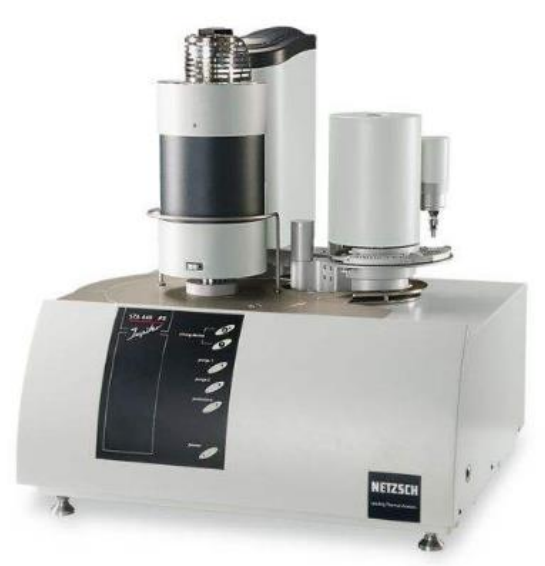

(a)

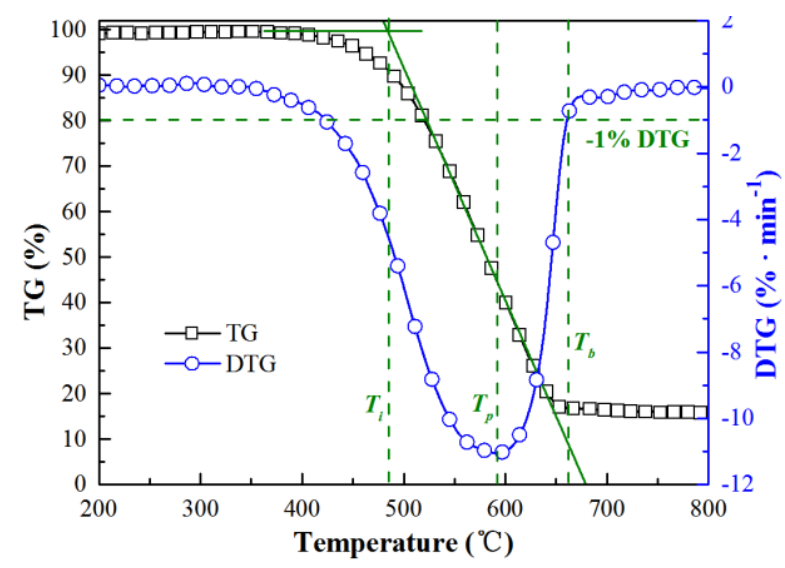

(b)

Figure 1. (a) Netzsch thermogravimetric analyzer; (b) the ignition and burnout temperatures.

According to thermo-gravimetric analysis curves, there are several methods that are used to determine the ignition and burnout temperatures. They are usually slightly different for different methods. In this study, the ignition temperature $T_{i}$ is obtained according to the TG-DTG curve method (as shown in Figure 1b) [21]. A tangent line on the TG curve is taken as the peak temperature $T_{p}$ corresponding to the maximum weight loss rate on the FTG curve, and the temperature at the intersection of the tangent line and the initial horizontal line of the reaction on the TG curve is the ignition temperature $T_{i}$. The burnout temperature $T_{b}$ is defined as the temperature at which the combustion rate exceeds $-1(\mathrm{wt}, \% / \mathrm{min})$ at the end of a major combustion process. More details are shown in Figure 1.

In order to evaluate the burning performance of coal, the comprehensive combustion index $(C C I)$ is defined as follows [22]:

$$
C C I=\frac{(d W / d t)_{\max }(d W / d t)_{\text {mean }}}{T_{i}^{2} T_{b}}
$$

where $(d W / d t)_{\max }$ is the maximum combustion rate, $(d W / d t)_{\text {mean }}$ is the average mass loss rate, $T_{i}$ is the ignition temperature and $T_{b}$ is the burnout temperature.

In this study, Coats-Redfern integral method is used to analyze the kinetic parameters $[21,23,24]$. The kinetic equation can generally be written as:

$$
\begin{gathered}
\frac{d \alpha}{d t}=k(T) f(\alpha) \\
k(T)=A \exp \left(-\frac{E}{R T}\right) \\
f(\alpha)=(1-\alpha)^{n}
\end{gathered}
$$

where $t(\mathrm{~s})$ is time; $\alpha$ is the conversion degree, $\alpha=\left(m_{0}-m_{t}\right) /\left(m_{0}-m_{\infty}\right), m_{0}$ is the initial mass of the sample, $m_{t}$ is the mass of the sample at time $t, m_{\infty}$ the final mass of the sample in the reaction; $T(\mathrm{~K})$ is the absolute temperature; $A\left(\mathrm{~s}^{-1}\right)$ is pre-exponential or frequency 
factor, $E\left(\mathrm{~kJ} \cdot \mathrm{mol}^{-1}\right)$ is the activation energy and $R\left(\mathrm{~kJ} \cdot \mathrm{mol}^{-1} \cdot \mathrm{K}^{-1}\right)$ is $8.3145 \mathrm{~kJ} \cdot \mathrm{mol}^{-1} \cdot \mathrm{K}^{-1}$ (the universal gas constant).

Inserting Equations (3) and (4) in Equation (2), we obtain the kinetic equation in the following form:

$$
\frac{d \alpha}{d t}=A \exp \left(-\frac{E}{R T}\right)(1-\alpha)^{n}
$$

where $\beta=d T / d t$ is the heating rate and $\mathrm{n}$ is the reaction order. Equation (5) could be transferred to

$$
\frac{d \alpha}{(1-\alpha)^{n}}=\frac{A}{\beta} \exp \left(-\frac{E}{R T}\right) d T
$$

Therefore, Coats-Redfern equation can be obtained by integration of Equation (6) as follows:

$$
\begin{gathered}
n=1, \ln \left\{\frac{-\ln (1-\alpha)}{T^{2}}\right\}=\ln \left\{\frac{A R}{\beta E}\left[1-\frac{2 R T}{E}\right]\right\}-\frac{E}{R T} \\
n \neq 1, \ln \left\{\frac{1-(1-\alpha)^{(1-n)}}{T^{2}(1-n)}\right\}=\ln \left\{\frac{A R}{\beta E}\left[1-\frac{2 R T}{E}\right]\right\}-\frac{E}{R T}
\end{gathered}
$$

For the actual combustion process, $E / R T \geq 1$ and $1-2 R T / E \approx 1$, so Equations (7) and (8) can be simplified as:

$$
\begin{gathered}
n=1, \ln \left\{\frac{-\ln (1-\alpha)}{T^{2}}\right\}=\ln \left\{\frac{A R}{\beta E}\right\}-\frac{E}{R T} \\
n \neq 1, \ln \left\{\frac{1-(1-\alpha)^{(1-n)}}{T^{2}(1-n)}\right\}=\ln \left\{\frac{A R}{\beta E}\right\}-\frac{E}{R T}
\end{gathered}
$$

In order to obtain kinetic parameters, coal combustion can be assumed as first-order reaction, using the Coats-Redfern equation above to calculate the apparent activation energy $E$ and pre-exponential factor $A$. Thus a plot of $\ln \left|-\ln (1-\alpha) / T^{2}\right|$ versus $1 / T$ should result in a straight line with the slope equal to $-E / R$ for the first-order kinetics. Therefore, the data in Coats-Redfern kinetic analysis were obtained by taking the reaction order as unity.

\section{Results and Discussion}

\subsection{Co-Firing Behavior of Semi-Char and Straw under Different Blending Ratios in $21 \% \mathrm{O}_{2} / 79 \%$ $\mathrm{CO}_{2}$ Mixtures}

The TG and DTG curves of semi-char co-firing with biomass are shown in Figure 2. It can be seen that semi-char and biomass show large differences in combustion behaviors, and these curves show similar regulation in two different atmospheres. The TG curve of SHC presents only one peak (about $600^{\circ} \mathrm{C}$ ), and the combustion of fixed carbon mainly occurs at this stage. The TG curve of ST shows three peaks (i.e., three stages). The first stage extends from about $250{ }^{\circ} \mathrm{C}$ to $350{ }^{\circ} \mathrm{C}$, which is the ST volatile combustion. The second stage extends from about 350 to $450{ }^{\circ} \mathrm{C}$, which is the ST fixed-carbon combustion. The third stage extends from about 450 to $550{ }^{\circ} \mathrm{C}$, which is the residual-char combustion and the decomposition of the difficult pyrolytic material [14]. For the blended fuels, each curve lays between those of the individual fuels and presents three peaks (i.e., three stages). The first stage (from about 250 to $350^{\circ} \mathrm{C}$ ) corresponds to the volatile combustion of ST; the second stage (from about 350 to $450{ }^{\circ} \mathrm{C}$ ) corresponds to the co-combustion of SHC and ST fixed-carbons, and the third stage (from about 450 to $550^{\circ} \mathrm{C}$ ) corresponds to the SHC fixedcarbon combustion and the decomposition of the difficult pyrolytic material of ST. While increasing the blending ratio of ST, the first and second peak values gradually increase, and the corresponding temperatures change slightly; the third peak value gradually decreases, and the corresponding temperature moves towards the lower temperature zone. 


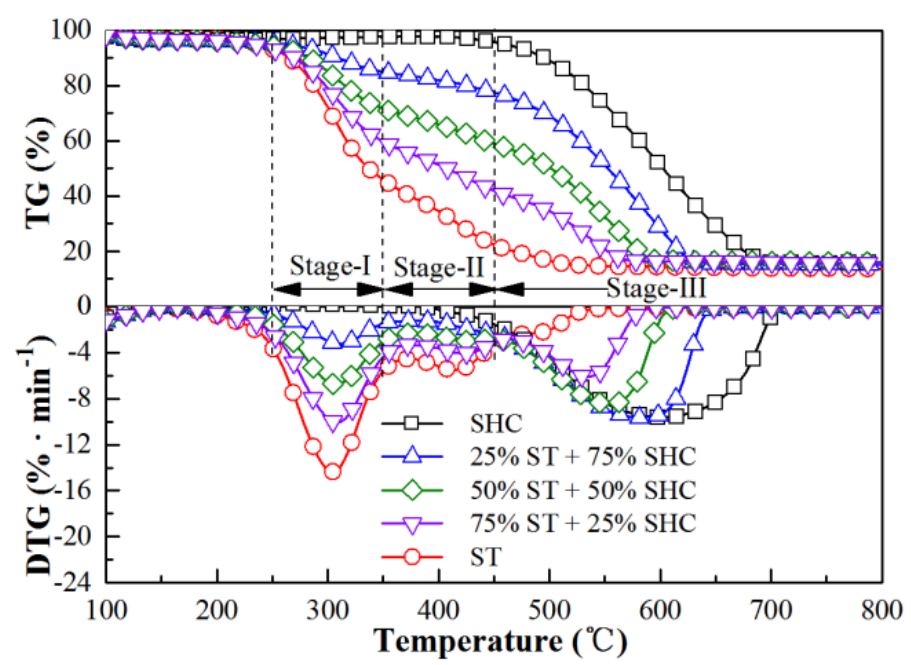

Figure 2. TG and DTG curves under different $\mathrm{ST}$ blending ratios $\left(20^{\circ} \mathrm{C} / \mathrm{min}, 21 \% \mathrm{O}_{2} / 79 \% \mathrm{CO}_{2}\right)$.

Figure 3 shows the ignition and burnout temperatures and comprehensive combustion index. It is obviously seen that the ignition temperature Ti of SHC is significantly higher than that of ST. For the semi-char co-firing with biomass, as the proportion of ST increases from 25 to $100 \%$, the change of the blended ignition temperature Ti is slight, which indicates that the ignition temperature Ti of blended fuels is mainly determined by the ST. As the proportion of ST increases from 0 to $100 \%$, the burnout temperature $\mathrm{Tb}$ decreases greatly and linearly. Results in Figure $3 \mathrm{~b}$ show that as the proportion of ST increases, the comprehensive combustion index CCI increases non-linearly, and the CCI increases gradually with the increasing blending ratio from $0 \%$ to $75 \%$ and increases significantly with the increasing blending ratio from $75 \%$ to $100 \%$. The explanation for this phenomenon may be that ST is added to SHC so that there is a synergy. These show that adding ST can effectively reduce the ignition temperature and burnout temperature of the sample.
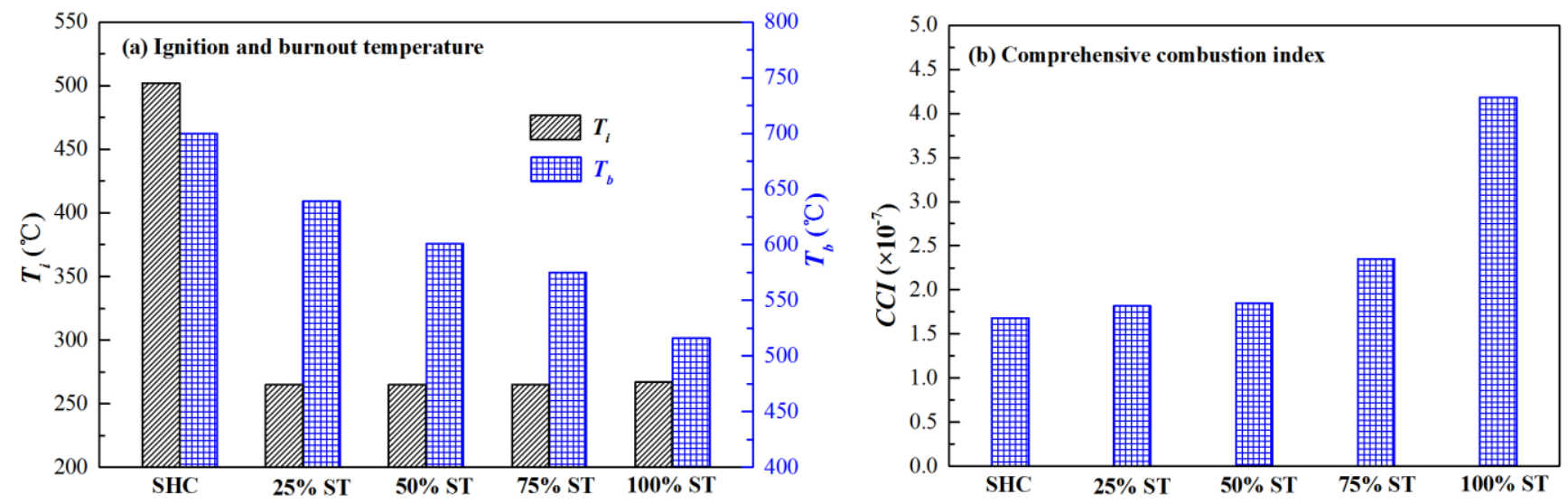

Figure 3. Ignition and burnout temperatures, $\mathrm{CCI}$ under different $\mathrm{ST}$ blending ratios $\left(20^{\circ} \mathrm{C} / \mathrm{min}, 21 \% \mathrm{O}_{2} / 79 \% \mathrm{CO}_{2}\right)$.

In order to evaluate the effect of the ST blending ratio on the combustion characteristics, the kinetic parameters ( $E$ and $\ln A$ ) under different blending ratios are obtained. In this study, in order to obtain the relatively accurate kinetic parameters, the kinetic analysis curves are divided into several segments according to the inflection point on the kinetic analysis curves. Additionally, the average activation energy $E$ and the average pre-exponential factor $\ln A$ are calculated from the following equation [21,25]:

$$
E=\sum E_{i} \cdot F_{i}
$$




$$
\ln A=\sum \ln A_{i} \cdot F_{i}
$$

where $E_{i}$ and $\ln A_{i}$ are the activation energy and the pre-exponential factor for each stage, respectively, and $F_{i}$ is the mass loss fractions for each stage.

The kinetic analysis curves of different blended coal combustion in $21 \% \mathrm{O}_{2} / 79 \%$ $\mathrm{CO}_{2}$ atmosphere are shown in Figure 4. Table 2 lists the activation energy $E$ values and the corresponding correlation factor $R^{2}$ of different blending ratios in $21 \% \mathrm{O}_{2} / 79 \% \mathrm{CO}_{2}$ atmosphere. It can be found that all activation energy $E$ values have a high correlation coefficient $\left(R^{2}\right)$, showing acceptable accuracy of the results. It can be seen that there is a similar trend. The total $E$ for the pure SHC is obviously higher than that for the pure ST. Additionally, the total $E$ reduces significantly after blending ST, but as the blending ratio increases from $25 \%$ to $100 \%$, E changes slowly due to the synergy between fuels. For different stages, $E$ and $\ln A$ present different regulations as the ST blending ratio increases. Compared to that of stage I and stage III, $E$ of stage II is significantly lower, and $\ln A$ is obviously higher. With an increasing blending ratio from $25 \%$ to $100 \%, E$ at stage I increases and $\ln A$ decreases; $E$ at stage II increases and $\ln A$ decreases as the blending ratio increases from $25 \%$ to $100 \%$.

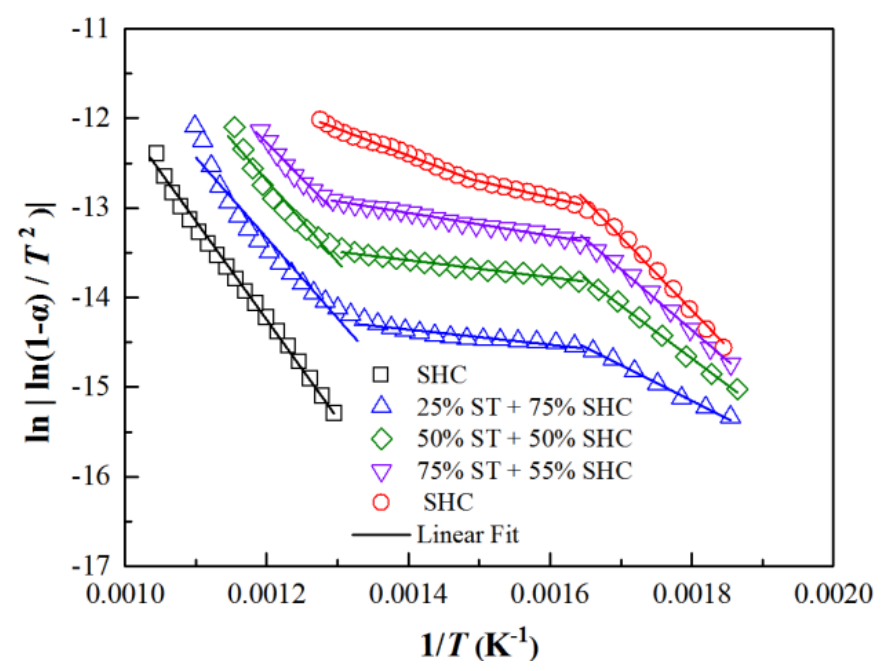

Figure 4. Kinetic analysis curves under different ST blending ratios.

Table 2. Kinetic parameters under different ST blending ratios.

\begin{tabular}{|c|c|c|c|c|c|c|c|}
\hline Item & Stages & $F_{i}(\%)$ & $E_{i}(\mathrm{~kJ} / \mathrm{mol})$ & $E(\mathrm{~kJ} / \mathrm{mol})$ & $\ln A_{i}\left(\mathrm{~s}^{-1}\right)$ & $\ln A\left(\mathrm{~s}^{-1}\right)$ & $R^{2}$ \\
\hline SHC & $502-700$ & - & - & 91.51 & - & 17.35 & 0.99117 \\
\hline \multirow{3}{*}{$25 \% \mathrm{ST}+75 \% \mathrm{SHC}$} & Stage I & 11 & 43.09 & \multirow{3}{*}{56.43} & 21.96 & \multirow{3}{*}{19.66} & 0.99550 \\
\hline & Stage II & 14 & 5.82 & & 25.63 & & 0.91626 \\
\hline & Stage III & 75 & 67.84 & & 18.21 & & 0.93601 \\
\hline \multirow{3}{*}{$50 \% \mathrm{ST}+50 \% \mathrm{SHC}$} & Stage I & 27 & 49.03 & \multirow{3}{*}{47.44} & 18.43 & \multirow{3}{*}{19.62} & 0.99590 \\
\hline & Stage II & 31 & 7.94 & & 24.79 & & 0.98230 \\
\hline & Stage III & 42 & 75.58 & & 16.58 & & 0.94467 \\
\hline \multirow{3}{*}{$75 \% \mathrm{ST}+25 \% \mathrm{SHC}$} & Stage I & 39 & 56.20 & \multirow{3}{*}{42.38} & 16.69 & \multirow{3}{*}{19.48} & 0.96747 \\
\hline & Stage II & 36 & 10.64 & & 23.99 & & 0.99330 \\
\hline & Stage III & 25 & 66.52 & & 17.35 & & 0.99529 \\
\hline \multirow{3}{*}{$100 \%$ ST } & Stage I & 54 & 67.93 & \multirow{3}{*}{46.18} & 14.13 & \multirow{3}{*}{17.96} & 0.99101 \\
\hline & Stage II & 20 & 15.18 & & 23.16 & & 0.99212 \\
\hline & Stage III & 26 & 24.833 & & 21.92 & & 0.99286 \\
\hline
\end{tabular}




\subsection{Co-Firing Behavior of Semi-Char and Straw under Different $\mathrm{O}_{2}$ Concentrations in $\mathrm{O}_{2} / \mathrm{CO}_{2}$ Mixture}

Figure 5 shows the TG and DTG curves of SHC, ST and 50\% SHC $+50 \%$ ST under different $\mathrm{O}_{2}$ concentrations in the $\mathrm{O}_{2} / \mathrm{CO}_{2}$ atmosphere. It can be seen that the effect of $\mathrm{O}_{2}$ concentration on combustion behavior is much stronger for SHC than ST (as shown in panels a and b of Figure 5). As a result, for the $50 \%$ SHC $+50 \%$ ST (as shown in panel c of Figure 5), the $\mathrm{O}_{2}$ concentration obviously affects stage III, and the TG and DTG curves of the third stage are obviously shifted to the lower temperature zone with increasing $\mathrm{O}_{2}$ concentrations. The mass-loss rate of the coal sample in high $\mathrm{O}_{2}$ concentrations is always higher than that in low $\mathrm{O}_{2}$ concentrations. Figure 6 presents the ignition and burnout temperatures and comprehensive combustion index of 50\% SHC + 50\% ST under different $\mathrm{O}_{2}$ concentrations. With increasing $\mathrm{O}_{2}$ concentration, Ti decreases slightly due to the slight effect of the $\mathrm{O}_{2}$ concentration on the ST ignition. A tendency for the burnout temperature $\mathrm{Tb}$ of the $50 \%$ SHC $+50 \%$ ST samples to decrease is observed as the oxygen concentration increases. As shown in Figure 6b, the comprehensive combustion index $C C I$ increases with an increase in oxygen concentration. This means that the increase in oxygen concentration is favorable for the burnout of the blended coal but slightly affects the ignition behavior of blended samples.
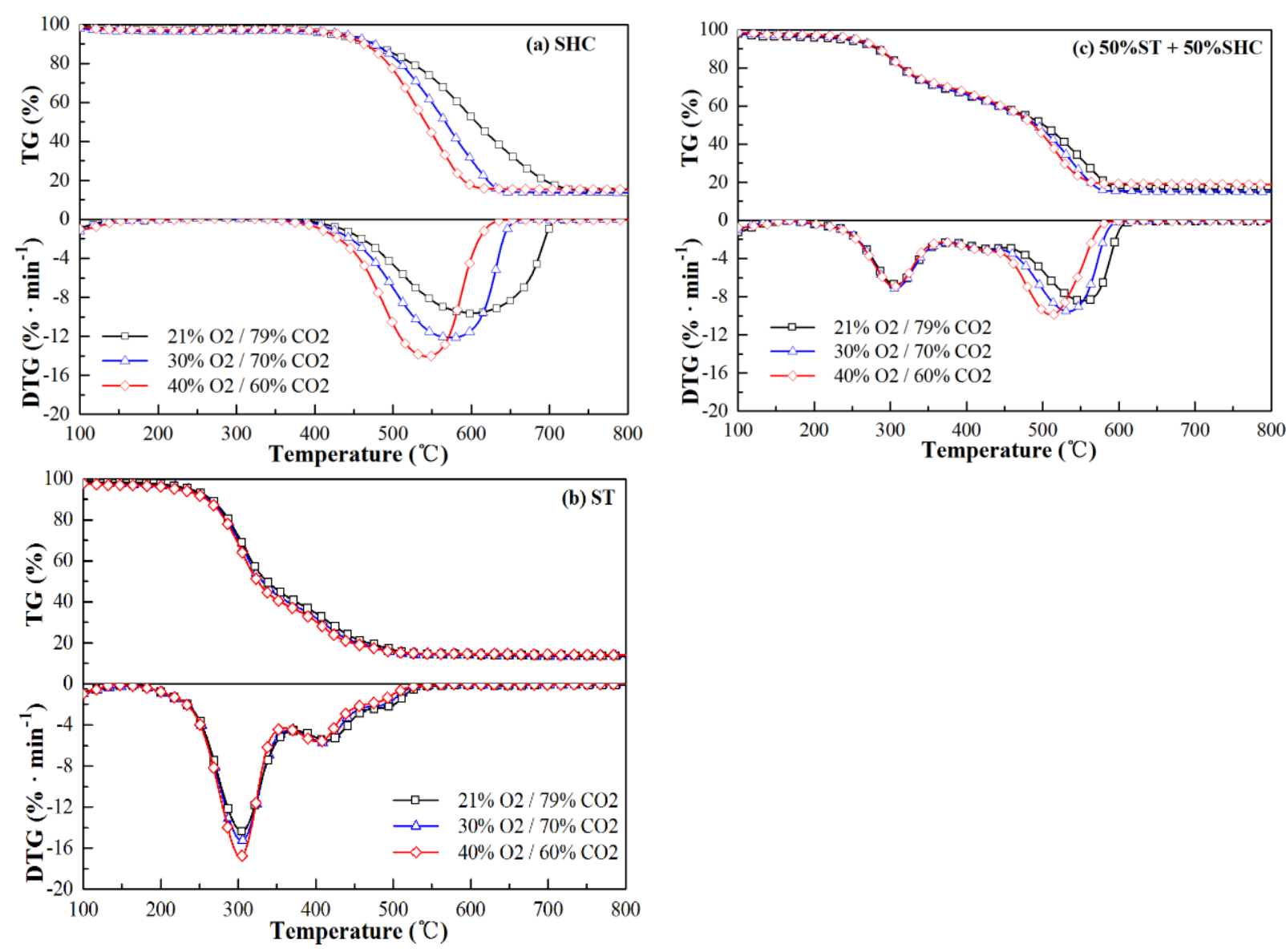

Figure 5. TG and DTG curves of SHC, ST and 50\% SHC $+50 \%$ ST under different $\mathrm{O}_{2}$ concentrations. 

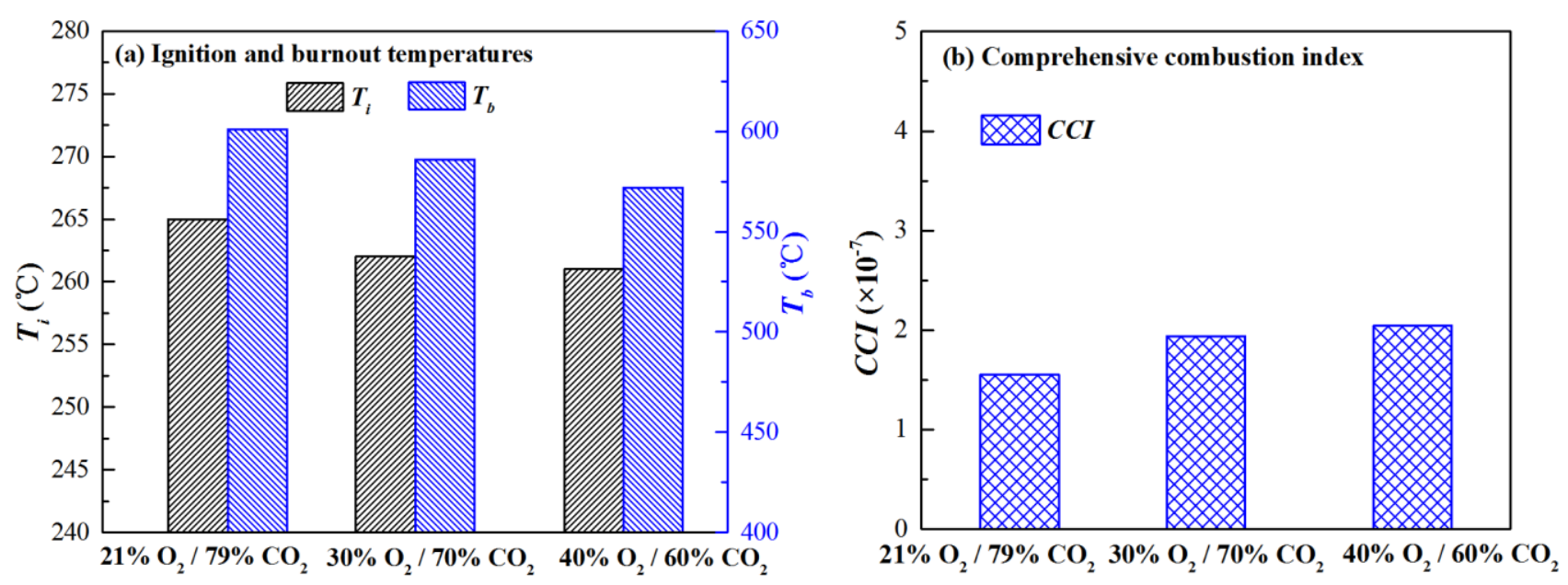

Figure 6. Ignition and burnout temperatures, $\mathrm{CCI}$ of $50 \% \mathrm{SHC}+50 \% \mathrm{ST}$ under different $\mathrm{O}_{2}$ concentrations.

In order to evaluate the effect of the $\mathrm{O}_{2}$ concentration on the combustion characteristics, the kinetic parameters $\left(E\right.$ and $\ln A$ ) of $50 \% \mathrm{SHC}+50 \%$ ST under different $\mathrm{O}_{2}$ concentrations is obtained. The kinetic analysis curves of $50 \% \mathrm{SHC}+50 \% \mathrm{ST}$ under different $\mathrm{O}_{2}$ concentrations are shown in Figure 7. Table 3 lists the activation energy $E$ values and the corresponding correlation factor $R^{2}$ of $50 \% \mathrm{SHC}+50 \% \mathrm{ST}$. For the three stages, similar regulation is observed. While increasing the oxygen concentration, the average activation energy $E$ gradually increases and the average pre-exponential factor $\ln A$ gradually decreases. According to existing reaction kinetic theory, the activation energy value can represent the difficulty of the reaction. An increase in oxygen concentration promotes the combustion reaction, which should have a lower activation energy [26,27]. However, in this study, the higher $\mathrm{O}_{2}$ concentration presents the highest activation energy and the lower pre-exponential factor. This phenomenon is in conformity with the experimental results of previous researchers [21,28,29]. For this phenomenon, Chen et al. [30] explained that during the sample combustion process, the activation energy is effected by the diffusion limitation and the reduction of the activated molecule concentration and the organic impurities. As the oxygen concentration increases, the heat release of the sample oxidation increases. In addition, the char structure increases the grain size and absorbs more ash, resulting in a corresponding increase in the final temperature [31]. Therefore, as the oxygen concentration increases, the activation energy increases.

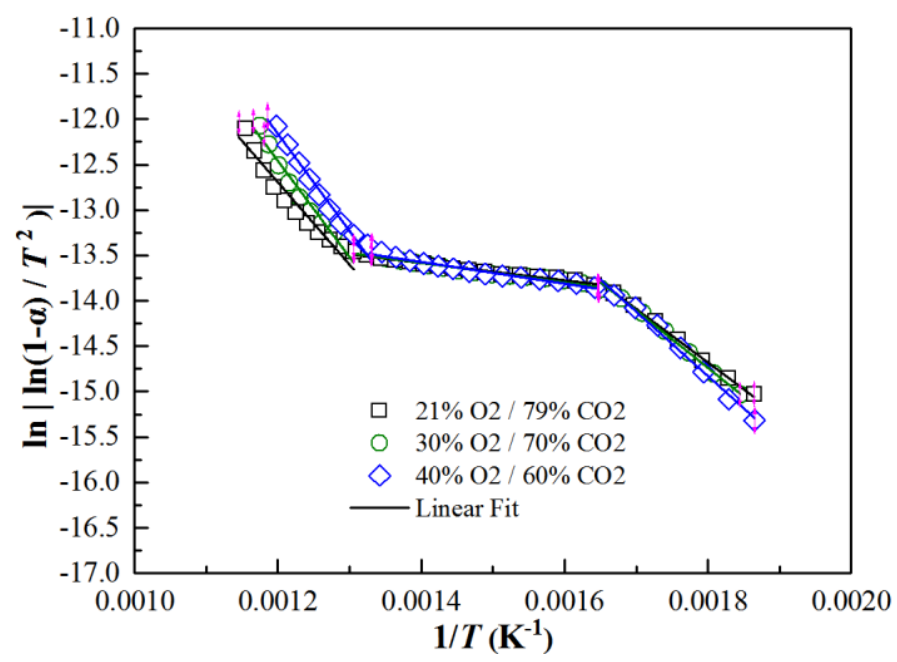

Figure 7. Kinetic analysis curves of $50 \% \mathrm{SHC}+50 \% \mathrm{ST}$ under different $\mathrm{O}_{2}$ concentrations. 
Table 3. Kinetic parameters of 50\% SHC $+50 \%$ ST under different $\mathrm{O}_{2}$ concentrations.

\begin{tabular}{|c|c|c|c|c|c|c|c|}
\hline Item & Stages & $F_{i}(\%)$ & $E_{i}(\mathrm{~kJ} / \mathrm{mol})$ & $E(\mathrm{~kJ} / \mathrm{mol})$ & $\ln A_{i}\left(\mathrm{~s}^{-1}\right)$ & $\ln A\left(\mathrm{~s}^{-1}\right)$ & $R^{2}$ \\
\hline \multirow{3}{*}{$21 \% \mathrm{O}_{2} / 79 \% \mathrm{CO}_{2}$} & Stage I & 27 & 49.03 & \multirow{3}{*}{47.44} & 18.43 & \multirow{3}{*}{19.62} & 0.99590 \\
\hline & Stage II & 31 & 7.94 & & 24.79 & & 0.98230 \\
\hline & Stage III & 42 & 75.58 & & 16.58 & & 0.94467 \\
\hline \multirow{3}{*}{$30 \% \mathrm{O}_{2} / 70 \% \mathrm{CO}_{2}$} & Stage I & 25 & 52.47 & \multirow{3}{*}{56.29} & 17.81 & \multirow{3}{*}{18.76} & 0.99377 \\
\hline & Stage II & 29 & 9.03 & & 24.74 & & 0.96212 \\
\hline & Stage III & 46 & 88.15 & & 15.52 & & 0.96876 \\
\hline \multirow{3}{*}{$40 \% \mathrm{O}_{2} / 60 \% \mathrm{CO}_{2}$} & Stage I & 24 & 58.92 & \multirow{3}{*}{57.33} & 16.62 & \multirow{3}{*}{18.61} & 0.99045 \\
\hline & Stage II & 31 & 9.924 & & 24.67 & & 0.95589 \\
\hline & Stage III & 45 & 89.14 & & 15.50 & & 0.98724 \\
\hline
\end{tabular}

\section{Conclusions}

This paper investigates the combustion behavior of semi-char co-firing with straw in $\mathrm{O}_{2} / \mathrm{CO}_{2}$ mixture using thermogravimetric analysis, which can can provide useful information for semi-char co-firing with biomass. The results show that each curve lays between those of the individual fuels and presents three peaks (i.e., three stages). The thermogravimetric curves of SHC co-firing with ST can be divided into three stages: the volatile combustion of ST, the co-combustion of SHC and ST fixed-carbons and the SHC fixed-carbon combustion and the decomposition of the difficult pyrolytic material of ST. Blending ST into the SHC can significantly decrease the ignition temperature and improve the comprehensive combustion behavior of blended samples. In increasing the proportion of ST from 25 to $100 \%$, the change of the blended ignition temperature is slight, but the burnout temperature decreases greatly. Kinetic parameters of combustion are calculated by using the Coats-Redfern integral method. Compared to that of stage I and stage III, the activation energy of stage II is significantly lower. In increasing the blending ratio from $25 \%$ to $100 \%$, the activation energy increases at stage I and decreases at stage III. Furthermore, the $\mathrm{O}_{2}$ concentration obviously affects stage III of $50 \%$ SHC $+50 \%$ ST and the thermogravimetric curves at this stage are obviously shifted to the lower temperature zone as the $\mathrm{O}_{2}$ concentration increases. The activation energy of $50 \%$ SHC $+50 \%$ ST increases as the oxygen concentration increases. Besides, the activation energy shows that the combustion characteristics cannot only be determined by the activation energy obtained by the Coats-Redfern method.

Author Contributions: Writing—original draft, D.L.; investigation, N.Z.; writing-review and editing, Y.F. project administration, Z.X. All authors have read and agreed to the published version of the manuscript.

Funding: This research was funded by Critical Technology Research and Integrated Application for Wastewater Resources and Zero Emission in High Water Consumption Enterprises (GDKJXM20183546).

Data Availability Statement: Data is contained within the article.

Acknowledgments: The support from the Guangdong Key Laboratory of Efficient and Clean Energy Utilization at the South China University of Technology, China, is gratefully acknowledged.

Conflicts of Interest: The authors declare no conflict of interest.

\section{References}

1. Zhang, L.; Hu, S.; Xu, K.; Jiang, L.; Wang, Y.; Su, S.; Xiao, Y.; Shan, L.; Shen, W.; Li, H. Study on the structural evolution of semi-chars and their solvent extracted materials during pyrolysis process of a Chinese low-rank coal. Fuel 2018, 214, 363-368. [CrossRef]

2. Li, C.Z. Importance of volatile-char interactions during the pyrolysis and gasification of low-rank fuels-A review. Fuel 2013, 112, 609-623. [CrossRef] 
3. Katalambula, H.; Gupta, R. Low-grade coals: A review of some prospective upgrading technologies. Energy Fuels 2009, 23, 3392-3405. [CrossRef]

4. Meng, F.; Yu, J.; Tahmasebi, A.; Han, Y.; Zhao, H.; Lucas, J.; Wall, T. Characteristics of chars from low-temperature pyrolysis of lignite. Energy Fuels 2013, 28, 5612-5622. [CrossRef]

5. Yao, Y.; Zhu, J.; Qinggang, L.; Zhou, Z. Experimental study on preheated combustion of pulverized semi-coke. J. Therm. Sci. 2015, 24, 370-377. [CrossRef]

6. Huang, Q.; Li, S.; Li, G.; Zhao, Y.; Yao, Q. Reduction of fine particulate matter by blending lignite with semi-char in a down-fired pulverized coal combustor. Fuel 2016, 181, 1162-1169. [CrossRef]

7. Yan, L.; He, B. On a clean power generation system with the co-gasification of biomass and coal in a quadruple fluidized bed gasifier. Bioresour. Technol. 2017, 235, 113-121. [CrossRef]

8. Gong, Z.Q.; Liu, Z.C.; Zhu, Z.P.; Yu, K.S.; Meng, G.J.; Liu, J.P.; Ouyang, Z.Q.; Sun, Y.K.; Liu, Q.G. Experimental study on semi-coke combustion and coal pyrolysis and combustion coupling. J. China Coal Soc. 2014, 39, 519-525. (In Chinese)

9. Jun, W.; Zhu, J.G.; Lu, Q.G. Experimental study on combustion characteristics and nox emissions of pulverized anthracite preheated by circulating fluidized bed. J. Therm. Sci. 2011, 20, 355-361.

10. Ouyang, Z.; Zhu, J.; Lu, Q. Experimental study on preheating and combustion characteristics of pulverized anthracite coal. Fuel 2013, 113, 122-127. [CrossRef]

11. Zheng, S.; Hu, Y.; Wang, Z.; Cheng, X. Experimental investigation on ignition and burnout characteristics of semi-coke and bituminous coal blends. J. Energy Inst. 2020, 93, 1373-1381. [CrossRef]

12. Zhang, J.P.; Jia, X.; Wang, C.A.; Zhao, N.; Wang, P.Q.; Che, D.F. Experimental investigation on combustion and NO formation characteristics of semi-coke and bituminous coal blends. Fuel 2019, 247, 87-96. [CrossRef]

13. Wang, Q.; Zhao, W.; Liu, H.; Jia, C.; Li, S. Interactions and kinetic analysis of oil shale semi-coke with cornstalk during co-combustion. Appl. Energy 2011, 88, 2080-2087. [CrossRef]

14. Liu, H.P.; Liang, W.X.; Qin, H.; Wang, Q. Thermal behavior of co-combustion of oil shale semi-coke with torrefied cornstalk. Appl. Therm. Eng. 2016, 109, 413-422. [CrossRef]

15. Liu, H.P.; Liang, W.X.; Qin, H.; Wang, Q. Synergy in co-combustion of oil shale semi-coke with torrefied cornstalk. Appl. Therm. Eng. 2016, 109, 653-662. [CrossRef]

16. Wall, T.; Liu, Y.; Spero, C.; Elliott, L.; Khare, S.; Rathnam, R.; Zeenathal, F.; Moghtaderi, B.; Buhre, B.; Cheng, S. An overview on oxyfuel coal combustion-State of the art research and technology development. Chem. Eng. Res. Des. 2009, 87, 1003-1016. [CrossRef]

17. Chen, L.; Yong, S.Z.; Ghoniem, A.F. Oxy-fuel combustion of pulverized coal: Characterization, fundamentals, stabilization and CFD modeling. Prog. Energy Combust. Sci. 2012, 38, 156-214. [CrossRef]

18. Buhre, B.J.P.; Elliott, L.K.; Sheng, C.D.; Gupta, R.P.; Wall, T.F. Oxy-fuel combustion technology for coal-fired power generation. Prog. Energy Combust. Sci. 2005, 31, 283-307. [CrossRef]

19. Wall, T.F. Combustion processes for carbon capture. Proc. Combust. Inst. 2007, 31, 31-47. [CrossRef]

20. Ma, L.; Wang, T.X.; Liu, J.C.; Fang, Q.Y.; Zhang, C.; Chen, G. Effect of different conditions on the combustion interactions of blended coals in $\mathrm{O}_{2} / \mathrm{CO}_{2}$ mixtures. J. Energy Inst. 2019, 92, 413-427. [CrossRef]

21. Tong, C.; Yang, X.; Chen, G.; Zhang, Y.; Chen, L.; Zhou, Y.; He, T.; Jin, B. Experimental investigation for the combustion characteristics of blends of three kinds of coal. Fuel 2021, 300, 120937. [CrossRef]

22. Sun, X.X. The Experiment Technology and Method of Boiler Combustion; Chinese Electrical Power Press: Beijing, China, 2002. (In Chinese)

23. Sutcu, H.; Piskin, S. Characterization and combustion kinetics of chars obtained from loquat stones. Combust. Sci. Technol. 2009, 181, 264-273. [CrossRef]

24. Yorulmaz, S.Y.; Atimtay, A.T. Investigation of combustion kinetics of treated and untreated waste wood samples with thermogravimetric analysis. Fuel Process. Technol. 2009, 90, 939-946. [CrossRef]

25. Wang, C.A.; Liu, Y.; Zhang, X.; Che, D.F. A study on coal properties and combustion characteristics of blended coals in northwestern China. Energy Fuels 2011, 25, 3634-3645. [CrossRef]

26. Shen, G.D.; Wang, Z.Q.; Wu, J.L.; He, T.; Li, J.Q.; Yang, J.; Wu, J.H. Combustion characteristics of low-rank coal chars in $\mathrm{O}_{2} / \mathrm{CO}_{2}$, $\mathrm{O}_{2} / \mathrm{N}_{2}$ and $\mathrm{O}_{2} /$ Ar by TGA. J. Fuel Chem. Technol. 2016, 44, 1066-1073. [CrossRef]

27. Masel, R.I. Chemical Kinetics, Catalysis; Wiley-Interscience: New York, NY, USA, 2001.

28. Chen, C.X.; Ma, X.Q.; Liu, K. Thermogravimetric analysis of microalgae combustion under different oxygen supply concentrations. J. Appl. Energy 2011, 88, 3189-3196. [CrossRef]

29. Liu, G.H.; Ma, X.Q.; Yu, Z.S. Experimental and kinetic modeling of oxygen-enriched air combustion of municipal solid waste. J. Waste Manag. 2011, 29, 792-796. [CrossRef]

30. Chen, C.; Lu, Z.; Ma, X.; Long, J.; Peng, Y.; Hu, L.; Lu, Q. Oxy-fuel combustion characteristics and kinetics of microalgae Chlorella vulgaris by thermogravimetric analysis. Bioresour. Technol. 2013, 144, 563-571. [CrossRef]

31. Yao, H.; He, B.; Ding, G.; Tong, W.; Kuang, Y. Thermogravimetric analyses of oxy-fuel co-combustion of semi-coke and bituminous coal. Appl. Therm. Eng. 2019, 156, 708-721. [CrossRef] 